\section{Microcomputers in the School Media} Center

by L.F. (Len) Proctor, Ph.D.

Rationale

why teacher librarians, media specialists and classroom teachers should be microcomputer the use be and secondary school systems.
First, within the context of the school tionally been seen to be the logical place non-print resources needed to support the
school curricula. Microcomputers have hardware components. These comof acquisition, utilization and mainte-
nance as other educational media. Similarly, microcomputers have software components (programs) which are subject tion, organization and utilization as print resources.

(T) recent advances in advances in mass storage technology, are combined with communications ad vances, this new technology will change
the way that media centers operate and the way that media centers operate an teract with their students. Third, with the advent and ready
availability of the microcomputer to the consumer in the mickelplace and the perin science, business, and industry; the current impact of the microcomputer on education is only beginning to be felt.
Educators in general and media specialists in particular will have to com novation. The most important question to
be answered here is, "to what use will be answered here is, 't
this innovation be put?

There are at least three answers to this
The toach "about" cst case, there is a nee rchitecture, computer programming an

Dr. Len Proctor is with the
Department of Comminication College of Education
University of Saskatchewan computer systems. Courses of this natur be responsible for teaching computer
science in the schools. In the second case there is need to teach specific conten use of computers by all teachers at all which is useful to facilitate the teaching/learning process. In the thir puters, ie. use of computers as an exten
sion of one's own capabilities or as a personal productivity tool.

For example, word processors can facilitate the creative writing process
because they make the process of successive revision relatively painless. of communication and remove the barrie of distance between the user and the
source of information. Database managers can extend memory capabilities
and promote the refinement of searching can simplify many tasks that require the

Focus of the paper

The purpose of this paper, therefore,
was to review current thinking on the subjects of microcomputer hardware selection, microcomputer software selec-
tion and the utilization of microcomliterature related to the automation of
school library services, K-12 has previously been reported by Twadd
1979) Givens (1981) conducted a of media centers throughout the U.S. to determine how computers are being
utilized by these centers, the levels of whether or not the services being providBoth these studies however have concentrated their efforts largely on main-frame
systems. This paper focuses, therefore, on
the microcomputer. and sorting skills. Finally spreadsheets puters in the school media center. Th
results of a survey of the profession ed by the computer are cost effective.
HARDWARE SELECTION One of the most objective assessments
of the issues related to the selection of microcomputer hardware selection of mary of a Minnesota Educational Com puting Consortium (MECC) study presented by Haugo (1981). While his
report was concerned specifically with the management applications of microcomputers, the same basic considerations are still pertinent to any other applications situation. With regard to the
actual specification of hardware and software for media center application, John
Blair - Computer Applications Librarian for the Medical Sciences Library at Texas A \& M University, has presented one of the most lucid explanations of the world have appeared in a series of articles in the have appeared in
journal, On-line

The components

Briefly stated, a microcomputer con列 tion contains the central processor (CPU). arguments abound with regard to how fast the "brains" (CPU) of the microcomputer should be able to operate and how ter MECC Haugo (1981) reported by MECC concluded the processor speed of the current crop of microcomputers, when compared to large mainframe compotential daily appliction most of the setting, speed was not a critical factor,
and therefore adequate. As far as memory size was concerned, $32 \mathrm{~K}$ of random acadequate for most of the potential practical applications. However, it was noted that the memory size can easily be inThis mined to $64 \mathrm{~K}$ or $128 \mathrm{~K}$ at minimal cost. decreased processing time for some applications that required the performance of extensive sorting routines.
To be useful, in addition to the "black box", a microcomputer must have a way display the results of its operations. These devices are known as peripherals or input and oulpul is the put mode is the typewriter keyboard
which is often seen directly attached to most microcomputers. However, several other input modes are possible and
desirable. They may take the form of a disk drive, upload/download connection
from another computer, light pen, graphics tablet, game padde pand/or
microphone. While cassette tape systems microphone. While cassette tape systems
have been used in the past as storage have been used in the past as storage
devices, they have almost totally fallen by the wayside because of their slowness

The most common output mode is the television screen which may also be per-
manently attatched to the "black box" or appear in the form of a standard television set. Disk and cassette output storage pherals, a hard copy printer can be very useful.

In any event, while it is possible to debate the merits of each of these devices
at length, there is no way in which to specify which microcomputer system should be purchased for a media center because it "depends on your special
needs" (Sharp and Smith, 1980, p. 20). The important point to be made here is availability, suitable equipment exists which can be assembled to meet speciftic

SOFTWARE CONSIDERATIONS

The school media specialist who is thinking about starting to use a presented with one), will quickly discover that programming or creating the software for a microcomputer is not a trivial
task. Just as in the production of a television program, a motion picture or slide ware is time consuming and expensive. The wise microcomputer user will follow ent: first, adopt: if you can't adop directly, then adapt; and only if you $^{2}$ cant adopt or adapt, develop.

Compatibility and packaged software microcomputers presents some special problems for the school media specialist.
As Woolls and Loertscher (1982) point As Woolls and Loertscher (1982) poin of manufacturing standards in existence. This means that the software is not inter changeable. It cannot be used on any
machine in the same way that a cassette audiotape will function in any manufac ware dictates equal variety among soft-

the programs you purchase must be and Loertscher, 1982, p. 22). The implica tion is, that of the present omputer is not
the software for the microcomputer only applications dependent, but it is
machine and/or system dependent.

Preview privileges

The situation is further complicated by specialists have been able to order nonprint materials with "on approval"
privileges. It would only seem natural to xpect the same process to occur when
earching for microcomputer software However, as reported by Glotfelty $(1982)$,
this was not to be the case. Media this was not to be the case. Media
specialists and librarians "have found that not all computer producers are willing to submit educational programs for
preview. Printed reviews are helpful, but oday's tight budgets necessitate checkin needs of each situation before purchase Glotfelty, 1982, p. 91).

Summary

To conclude this discussion of hardsuggested that given specific parameters, will arise to fit the needs assessment of any situation. Secondly, it has been furany situation. Secondly, it has been fur-
ther suggested the real essence of the microcomputers for education involves
the programs that run on the machines. the programs that run on the machines,
"The tricky decision to make is what software (program) is best for a particular apnature of the available commercial sofware (Blair, 1981, p. 91).
Many individuals, when first in vestigating the use of microcomputers ar likely to be most impressed by the equip.
ment, and overlook the fact that in the long haul, their main investment will be
in software. As computer needs grow, more software is purchased. The cost along with the cost of training "will probably dwarf the
(Falk, 1981 p. 29 )

The remaining portion of this paper has computers may be used in a media center and has identified some commercially would fulfill the needs of a specified application.

"What libraries do often boils down to where a certain item is located on the shelf and in the ordering, circulation, or 19). "A micro can handle almost any tex "A " to Lundeen (1980), "In the area of applications software, there is a vast array pre arlable that is written specifically for ibraries" (Lundeen, 1980, p. 184 However, there are a number of smal ple, The Controller by Apple, that can be readily adapted to process order initiation, order receiving, and the inve
control of instructional resources.

Data-base creation and management package

Operating at the most elementary leve Sugranes (1980) was able to use a free, called File Cabinet to create bibliographic database which contained a center. Students were able to gain acce subject This program was also used to produce
triculum related bibliographies for the teachers in addition to being used to conFrom a listin AV equipment inventorit could easily be determined what projects were checked out to which parA more sophisticated version of the A ware Microcomputer Products. This program, as described by Blair (1982d), is specialist. It incorporates powerful repo formating commands. Multiple primary and secondary search keys for both prin ting and displaying records are easily documentation is helpful in that it has many tutorial exercises available. These design of one's own files and file mana ment systems a fairly easy task. described in the literature was the system devised by Betty Costa (1981), Costa and 
specialist. Both of the previously describ-
ed systems, when used to set up an on-
line catalog for a large school center, could run into storage capacity or To avoid this concern, Costa's system taken advantage of the larger storage
capacity of a hard disk system. However a customized program was required to
handle the operation of the system. While handle the operation of the system. Whil
this was not difficult to obtain, it makes this system one step removed from the off-the-shelf packaged program. Each of these examples demonstrates
the file management capabilities of the microcomputer. When used correctly. quisitions file, an overdue list or an equipment inventory listing and generate the
revised versions of the lists with revised versions of the lists with
minimum of clerical effort. In addition, special utilities packages for program ment statistics and, if it is required for reporting purposes, turn these statistics
into computer generated graphs or charts.

Telecomputing

The electronic universe is in fact a com
munity of computer users. The comm denominator is the telephone line and micro computers mainframe, min who own or use them) can "talk" to each other. Thus, anyone who owns or has ac-
cess to any kind of computer may join the network by plugging into a telephon ing a telephone number (Hurly, Lauch

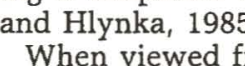

When viewed from this perspective, can in fact be seen that today's online in
formation industry has evolved from the remote data processing services that
began in the late 1950 's as a low-cost alternative to buying or leasing a mainmicrochip era, only big government and big industry could afford to have their own on-site mainframe computers. While
smaller organizations may have needed the power of that particular type of com
puter, cost factors made a time-shared system the only viable alternative. The result was the creation of a delivery of computers, specialized software, standards, protocols, electronic packet-
switching networks, and other industry components capable of reliably transm ting information from one computer to
another. Once the delivery mechanism was in place, it was only a function of
time before individuals and companies began to find ways to use this system for something other than transmitting the
day's banking transactions to a remote mainframe computer. Thus the only obstacle inhibiting the expansion of this
embryonic network was the cost of the delivery mechanism.

With this program, the user can type in
labels, numbers and formulas at each in matrix is set up thews. Once

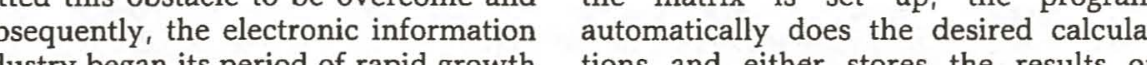
During this period of rapid growth and evelopment, a bewildering array of
stems and services have developed most overnight. Observing the players dustry is a fascinating ativity to watch, but a difficult situation to classify into a unified system for descriptive purposes. Three databases however, currently fit ion utility". They are The Source, Compuserve and the Dow Jones fewstres serve to distinguish an information utility from other types of organiza. tion retrieval that has been designed to be used by the average user rather than by a professional researcher. To serve the contains information on a wide range of any one subject. Second, in providin access to a database, each utility also of fers services. These services may include
such things as electronic mail delivery, banking, shopping, real-time communication, game playing with other system run programs on the mainframe On the other side of the coin, en cyclopedic database organizations offer
the user access to "in depth" types of in formation. The major comptypes of ininto this category are DIALOG, BRS, and ORBIr. Each organization can be thought of as a convenient delivery system or
gateway service that enables the user to search over 200 databases, covering dissertation abstracts, on-line. In this context, these companies are essentially in-
formation brokers. They strike a contract with an independent company that formation according to the needs of their particular system and offer it to the user point of view, they are helpful, intermediary agents who handle all of the
billing of telephone lines and computer billing of telephone lines and computer rangements with the database

Decision-making aids

the VisiCalc program. VisiCatc the use of tronic spreadsheet which is formatted like a matrix. The regular version can Extended versions are readily available. word processing capability of microcon puters can be gained by even a cursory
examination of the trade journals. For ex ample the July-August, 1982 issue of Apple II microcomputer alone. Today, packages for the Apple. Similar patterns re observable in virtually all the other popular brands of micro's

TEACHING APPLICATIONS

If microcomputers are to be located in the media center, it is only reasonable to
expect that some form of instruction cur. In fact, according to Davies (1979). "Today's school library media specialis is a teacher in the broadest sense of the titude, in function, and in commitment. The responsibility of this position extends far beyond organizing and maintaining a meurh 1979, p. 63). Teaching about computers may follow
two tracks, computer literacy and comtwo tracks, computer literacy and com-
puting literacy. Computer literacy refers puting literacy. Computer literacy refers
to students learning how a computer works and how to program a computer. Computer literacy is treated as an end

On the other hand, computing
On to
literacy refers to students learning how literacy refers to students learning how
to use microcomputers as tools for the enrichment of their personal and professional lives. Computers are seen as aids to solving problems and extensions of
human abilities such as memory. There is no reason why student volunteers in the
school media center could not be taught school media center could not be taught
to use any of the previously described file management or word processing packages to
media center.

The teaching role adopted by the school Tedia specialist will be a function of the tise, and enthusiasm. The media specialist may adopt the role of "teacher
buff" |Grossnickle and Laird, 1981). In buff" | Grossnickle and Laird, "1981). In
addition to providing regular services to ship role requires the devotion of
substantial amount of time, energy and effort to developing in-service trainin the media specialist may elect to ignore all, Kemp et al. (1980) have observed that the track record for the adoption of media in the classroom has been littered with time, there is not any foreseeable reaso why the microcomputer will not go the same route. e, between these two exand understanding hosition exists. Tac and understanding however, must
prevail. It is not unusual for the math or by simulating the actual outcomes gain that elementary students, who have ecome familiar with a microcomputer,
already knew how to type prior to coming knows that high school is the proper place to learn this skill - not elementary school! Following this line of reasoning, "Diction anyone who promoted the use of "Dictionary programs by students to
correct the spelling of their themes RECREATION

The drawing power of microcomputers
for both young and old, has been demonstrated by such organizations as ears ago because that was the loca hangout for kids. Now they hang out at
the computers" (Harvie, 1981, p. 604 ). This project began when a couple of loc
businessmen donated five micros to the library. By late fall, 1980 , the National
Science Foundation had been convinced So provide a $\$ 224,000$. 00 grant so that
everyone in Menlo Park could have "Although playing games was the most did spend eight percent of their time propramming. Some children with previous hey had created, using ComputerTown advice of and support from other pleted their programming homework and a few enterprising pupils created proassignments" (Harvie, 1981, p. 604).
Some children came to associate libraries with computers. Harvey reports their sur-
prise at not finding micros in branch recorded by Vickery, (1981) and others. As an isolated instance, the previous Rather, it is suggested that this is not a be rapidly gaining in popularity both in Media center specialists should is popular, but rather as Rawitsch (1981) suggests because computers are "thinking" machines, and thinking is what education is all about. Second, many of real world concerns. Third, computers
make it easier to meet the special needs of students through individualized instruc ning into homes at an increasing rate Parents are beginning to demand similar An appreciation of the pop
Given the nature of computers, their pervasiveness in science, business and
their current accessibility to the consumer market, their impact is only beginmedia specialists in particular will have to new education to be answered by the media specialist is "to what use will it be put?"

ceveral possible answers were su potential for being able to reduce th mount of time a media specialist has to spend performing clerical tasks. Secondwhich to develop expertise. Both com puter literacy and computing literacy are he foreseeable future. Finally, medi specialists have a powerful motivationa
tool at their disposal. Perhaps, through ineracting with the microcomputer and the students will begin to view the medi source, rather than a place to be avoided.

REFERENCES

known. "Micro magic. (sometimes als air J.C. "Micros, minis and mainframes
A newcomers guide to the world of computers - especially micros." On 1982a. "Micro magic 'Canned' pro air, J.C. "Micro magic. 'Canned' pro-
grams: Panacea - or Pandora's Box? Online, Vol. 6, No. 3, p. 62-69, March,
1982b. Blair, J.C. "Micro magic. 'Plain vanilla'."
Online, Vol. 6, No. 5, p. 69-77, May, 1982c. " "Database designs. A tutoria in representative apple software." Blair, J.C. "Creating your own database." 1982e. "Min Colorado Costa, B. "Microcomputer in Colorado
It's elementary." Wilson Librar Bulletin, Vol. 55, No. 9, p. 676-67 osta, B. and Costa, M. A Micro hand-
book for small libraries and media
Continued on page 27 Continued on page
CONCLUSIONS Vol. 5, No. 10, p. 90-94, October, 198 
ning'. Computer logic and human logic do
not necessarily become one, but they complement each other as the child grows

The Need for Computer Literacy computers and education that does no stress the need to supply children (and
ultimately society) with knowledge about computers. The advent of microcom. puters has made this an even more urgent need. "The literature predicts that com-
puter literacy will be the next crisis in puter literacy will be the next crisis in
education ... the potential for computer illiteracy poses a challenge to the educational community which must not be ig-
nored" (Dickerson \& Pritchard, 1981, p. 7) nored" (Dickerson \& Pritchard, 1981, p. .7)
Molnar (1981) defines computer Molnar "1981 defines computer
literacy as "what a person needs to know and do with computers in order to function competently in our society"' (p. 27). It
is the 'do' that is the all-too-often forgotten element of computer literacy paper. Watt (undated) sees one category of computer literacy as being that of learning to program - a skill of problem-
solving, analyzing, and predicting The main issue here is that it is not sufficient to teach children about microcomputers; what the computer can do for with the computer (keeping in mind that powerful 'tool for learning, but they can also be a very effective medium of expression. whatever instructional method one chooses to employ), the control is no rather in the hands of the child. Learning and thinking become active, creative processes controlled by the learner! Designing such environments and takand other individual differences is a worthy goal for educators in the field of microcomputers and education. If create, to program, to 'represent' through microcomputer, then they are being denied the chance to develop creatively and education will be losing an oppormedia of expressions available. "Educators must take the lead in showing how this can be done by exploring the use can enhance subject metter lepter and student creativity"l (Critchfield, 1979, p. 18).

Conclusion

There is strong theoretical support for tween computers and children. As em26
Hall, G. Issues Related to the Implementation of Computers Presented at the N.I.E. Conference on Computer Technology in Schools (Washington). The University of Texas, Lawler, R. "Designing Computer-Based Microworlds." Byte. The Small Systens Journal, August 1982, 7/8 Levin, J. \& Kareev, Y. Personal Com puters and Education: The Human Information-Processing. University of California, San Diego, La Jolla, Cali " Crita. Chip gr, No Literacy: "Tre We Prepared for It?" Educational Technology, 1981, 21|1 Papert, S. Mindstorms: Children, Com puters, and Powerful Ideas. New
York: Basic Books Inc., 1980. Papert, S. Some Poetic and Social
Criteria for Education Design. Criteria for Education Design.
M.I.T., AI Lab, Logo Memo No. 7, June Papert, S. Uses of Technology To Logo Memo No. 8 June 1973. Papert, S. A Computer Laboratory for lementary Schools, M.I.T., AI Lab, Logo Memo No. 1, 1971a. Papert, S. Teaching Children Thinking.
M.I.T., AI Lab, Logo Memo No. 2 Papert, S. Teaching Children To Be Mathematicians vs. Teaching Abou Mathematics. M.I.T., AI Lab, Logo
Memo No. 4 July 1971c. Papert, S. \& Solomon, C. Twenty Things to do With a Computer. M.I.T., A Lab, Logo Memo No. 3, June 1971 .
Rainsberry, F. Dimensions of Visual The Ontario Institute for Studies in Education, 1975. Solomon, C. Leading a Child to a Com-
puter Culture. M.I.T., AI Lab, Log puter Culture. M.I.T., AI Lab, Logo Solomon, C. \& Papert, S. A Case Study of a Young Child Doing Turtle Graphics in Logo. M.I.T., AI Lab, Watt, D. "Logo in the Schools." Byte, The Small Systems Journal, 1982 7|8|, 116-134. Watt, D. Education for Citizenship in a
Computer-Based Society. M.I.T Winn, W. "Children, Cognition and Television". In C. Ungerleider (Ed.). Perspectives on Television Educa-
tion. (Ministry of Supply \& Services tion. (Ministry of Supply \& Services
Canada, Cat. No. CI 96-16/1981E. Ottawa, Canada: Beauregard Press Ltd. 1981

VOLUME 14, NUMBER 4, 1985
Haugo, J.E. "Management applications
of the microcomputer: promises and piffals. "AEDS, Vol. 14 , No. 4, p Inc., 198.
Davies, A. The school library media Falk, A. "Computer software and equipment considerations." School Library
Journal, Vol. 28, No. 3, p. 29-32, November, 1981 Givens, P.B. Computers and media centers: services, satisfaction and cost effectiveness. Resent 1981. ED 211 058 .

software." School Library Journal, Vol. 28, No. 7, p. 91-94, March, 1982. Grossnickle, D.R. and Laird, B.A. "Proschool uses microcomputers." Educational Technology, Vol. 21, No. 12, p.

arvie, B. "Out of the arcades and into Vol. 12 American Libraries, November, 1981. video, Laucht, M. and Hlynka, D. The New York: Harper \& Row, 1985.

Kemp, J., et al. "Fads, fallacies,
failures." Instructional Innovator, Vol. 25, No. 1, p. 25-27, January, 1980 undeen, G. "The role of microcomputers in libraries." Wilson Library
Bulletin, Vol. 55, No. 3, p. 178-185, November, 1980

Nicklin, R.C. and Tashner, J. "Micros in the library media center?" Schoo 168-181, Spring, 1981.

puters in libraries." of microcom-
pournal of Library Automation, Vol. 13, No. 1, p. 7-17, March, 1980

awitsch, D. "Implanting the computer in the classroom: Minnesota's Delta Kappan, Vol. 62, No. 6, p
453-454, 1981. spotlight." CMLEA Journal, Vol. 3 Strazdon, M.E. A library applicatio of the Apple VisiCalc program No. 1, p. 75-86, Winter, 1981 . Sugranes, "Microcomputer applimedia center." CMLEA Journal, Vol. 3, No. 2, p. 9-11, Spring, 1980. waddle, D R "Schol media services Quarly

Summer, 1979.
Vickery, C.A. Personal experiences: using microcomputers in a junio ED 208860. oolls, B.E. and Loertscher, D.V. "Some sure-fire microcomputer programs." School Library Journa
Vol. 28, No. 10, p. 22-23, August, 1982 . sonal Lear Directions for Long-Ter

Thn, T. Computers, Education, Children. Unpublished Manuscript
Berkeley: University of California

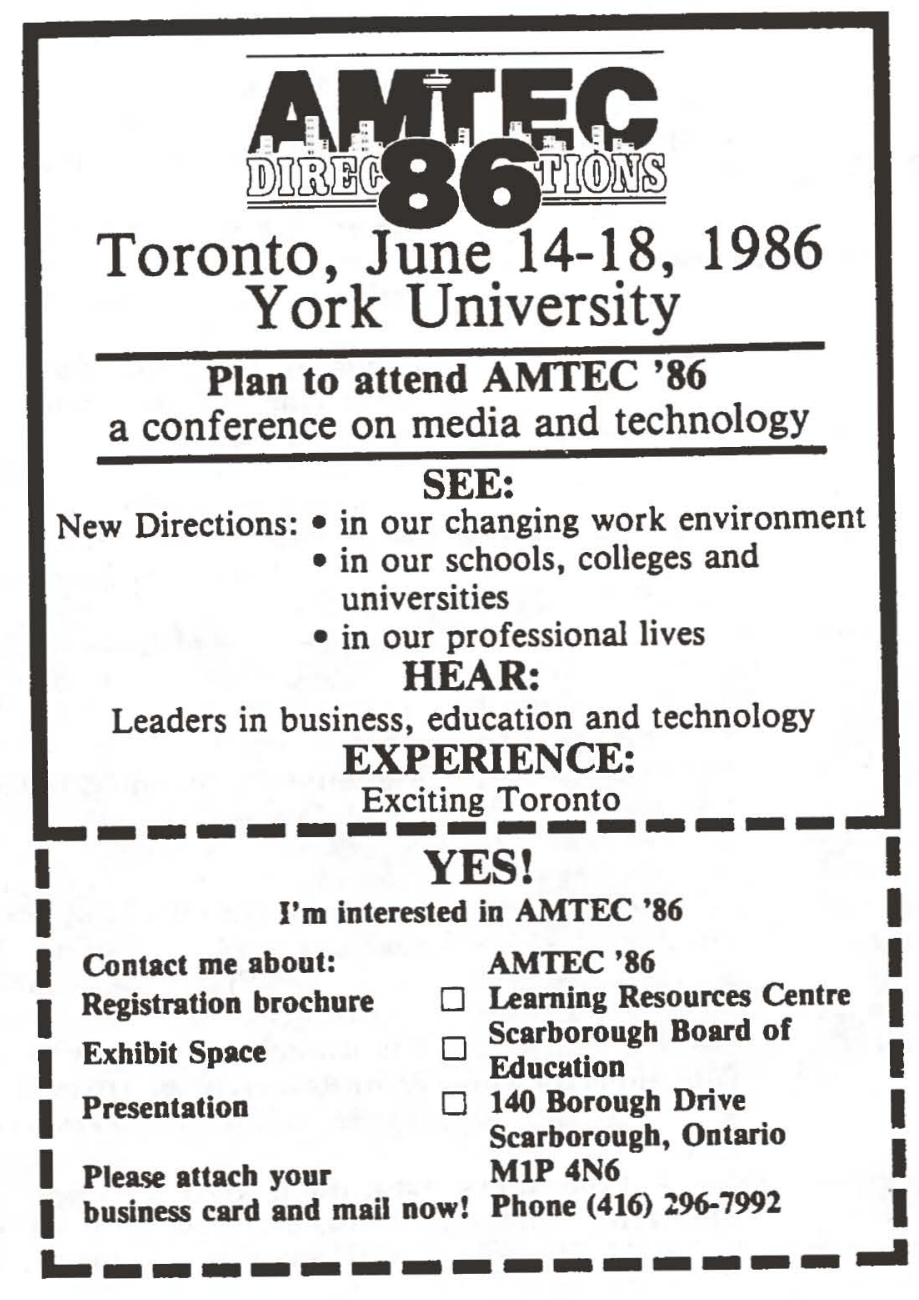

CANADIAN JOURNAL OF EDUCATIONAL COMMUNICATION 